\title{
Effect of the Presence of Siloxanes in Biogas Chemical Looping Combustion
}

\author{
Teresa Mendiara,* Arturo Cabello, María Teresa Izquierdo, Alberto Abad, Tobias Mattisson, \\ and Juan Adánez
}

Cite This: Energy Fuels 2021, 35, 14984-14994

Read Online

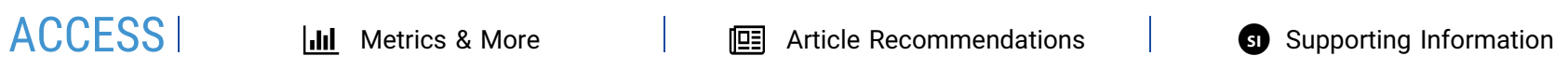

ABSTRACT: Siloxanes are a group of Si-based impurities,
common in biogas. Although normally present in relatively small
amounts, their presence could be highly problematic, as the
generated $\mathrm{Si}$ could be a precursor to abrasion and wear in
downstream components. In this work, the siloxane effect in biogas
chemical looping combustion ( $\mathrm{CLC}$ ) was evaluated. CLC of
biogas could be an efficient way of achieving $\mathrm{CO}_{2}$ negative
emissions. Two oxygen carriers (CuO-based and $\mathrm{Fe}_{2} \mathrm{O}_{3}$-based
residue) were used in the combustion of a simulated biogas stream
in a batch fluidized bed reactor. Here one of the most common
siloxane compounds (hexamethyldisiloxane, L2) was utilized together with methane, the most common combustible component

in biogas. The siloxane decomposed in the batch reactor, forming gaseous compounds and Si-based particles. The gaseous compounds formed (mainly $\mathrm{CO}, \mathrm{H}_{2}, \mathrm{CH}_{4}$, and $\mathrm{C}_{2}$ ) were able to react with the oxygen carrier, whereas the Si originating from the siloxane interacted with the oxygen carrier particles. Elemental analyses of samples obtained from the reactor bed after combustion experiments revealed that significant amounts of Si from siloxane could be found in the oxygen carrier. The X-ray photoelectron spectroscopy (XPS) analyses of the same samples showed that silica in the oxygen carrier was mainly found at the surface of the particles and in the form of $\mathrm{SiO}_{2}$ or silicates/aluminosilicates. The XPS results were in agreement with a theoretical thermodynamic analysis performed to determine the possible stable Si-based species that may be formed. Although the deposition/formation of silica compounds in the oxygen carrier may lead to the agglomeration of particles, such a phenomenon was not observed in the present work.

\section{INTRODUCTION}

The development of bioenergy technologies may accelerate energy transition to the low-carbon economy underlined in the Paris Agreement (2015). ${ }^{1}$ Biogas production has an important role among the bioenergy technologies because it favors the transition to a circular economy and significantly contributes to the reduction of greenhouse gas (GHG) emissions, improves waste management, and provides greater resource efficiency. Biogas consist of a mixture of mostly methane and $\mathrm{CO}_{2}$ generated in the anaerobic digestion of organic matter. Almost two-thirds of biogas production in 2018 was used to generate heat and electricity. Today, the power generation capacity running on biogas is $18 \mathrm{GW}$, mostly in Europe, the United States, and China. ${ }^{2}$ Moreover, on the basis of current policies, biogas consumption is expected to increase from an actual 35 Mtoe to around 95 and 150 Mtoe in 2030 and 2040, respectively. $^{3}$

The composition of raw biogas is determined by the type of substrate and the design of the production process, including biodigesters for agricultural residues, landfill gas recovery systems, and waste water treatment plants (WWTPs). In addition to methane and $\mathrm{CO}_{2}$, other minor compounds such as $\mathrm{H}_{2} \mathrm{O}, \mathrm{H}_{2}, \mathrm{O}_{2}, \mathrm{CO}$, and $\mathrm{N}_{2}$ can be present in biogas. ${ }^{4}$ Most of them are considered to be harmless, but biogas also contains small quantities (traces) of other compounds that can affect its further use in energy production. The most common is hydrogen sulfide $\left(\mathrm{H}_{2} \mathrm{~S}\right)$ together with mercaptans. The presence of these compounds may vary between 0.0001 and 1 vol \%, and they can cause corrosion and environmental problems once they are converted to $\mathrm{SO}_{2}$ during combustion. ${ }^{5}$ Another compound commonly formed is ammonia $\left(\mathrm{NH}_{3}\right)$, whose presence can vary between 0 and $100 \mathrm{ppm}_{\mathrm{v}}{ }^{4}$ Ammonia is also highly corrosive in the presence of water, and when combusted, it can be transformed into nitrogen oxides $\left(\mathrm{NO}_{x}\right)$. In addition, some studies point to siloxanes as one of the most

Received: June 21, 2021

Revised: August 12, 2021

Published: August 31, 2021 
problematic compounds in biogas. Siloxanes are linear (L) and cyclic (C) compounds that incorporate $\mathrm{Si}\left(\mathrm{CH}_{3}\right)_{2}-\mathrm{O}$ functional groups in their structure. ${ }^{6}$ The origin of siloxanes in biogas is found in organic silica compounds such as household (detergents), industrial (coating paints), and personal care products (shampoos, cosmetics), ${ }^{7}$ and thus they have been almost exclusively detected in biogas from landfills and WWTPs. ${ }^{8}$ Usually they are present at a trace level, but the final content depends on the origin of the biogas, as shown in Table $1{ }^{9}$

Table 1. Linear (L) and Cyclic (C) Siloxane Concentration Depending on the Biogas Origin ${ }^{9}$

\begin{tabular}{lll} 
& linear $(\mathrm{L})\left(\mathrm{mg} / \mathrm{m}^{3}\right)$ & cyclic $(\mathrm{C})\left(\mathrm{mg} / \mathrm{m}^{3}\right)$ \\
landfills & $6.0 \times 10^{-3}$ to 5.9 & $1.85 \times 10^{-2}$ to 42 \\
WWTPs & $11 \times 10^{-5}$ to 15.2 & $4.9 \times 10^{-3}$ to 340.7 \\
\hline
\end{tabular}

Siloxanes are also one of the current back stoppers for the widespread use of biogas as a renewable fuel in energy production because they may cause operational problems in the current biogas utilization systems, such as turbines, engines, or catalysts for steam reforming or fuel cells. Siloxanes decompose at high temperatures, generating silicates and $\mathrm{SiO}_{2}$, which can accumulate on the surface of pistons, cylinders, turbine blades, or internal combustion engine walls, causing abrasion and leading to failure of the equipment. $\mathrm{SiO}_{2}$ particles generated in combustion may also have implications in human health because they may be released as breathable nanoparticles $(40-70 \mathrm{~nm})$ with toxic effects. ${ }^{10}$ Moreover, they may represent an environmental hazard due to their potential toxicity and persistence. ${ }^{11}$ Considering this, engine manufacturers have set the maximum content for siloxanes in biogas in the range 0.03 to $28 \mathrm{mg} / \mathrm{Nm}^{3}$ so that in many cases, it will be necessary to remove them before using the biogas. ${ }^{12}$ Depending on the final application of biogas, not only the removal of siloxanes but also the removal of $\mathrm{CO}_{2}$ and other minor compounds is required. If biogas is to be used as a fuel for internal combustion engines, then the methane content should be $>90 \%$. $^{13}$ If biogas is to be used as biomethane and injected into the natural gas grid in Europe, then the methane content should be $>95 \%$, and the amounts of minor compound should be limited to $\mathrm{CO}_{2}<2 \%, \mathrm{O}_{2}<0.2$ to $0.5 \%, \mathrm{H}_{2} \mathrm{~S}<5 \mathrm{mg} /$ $\mathrm{m}^{3}$, and $\mathrm{NH}_{3}<3-20 \mathrm{mg} / \mathrm{m}^{3}$. ${ }^{14}$ Physical and chemical absorption technologies have been commonly used to remove $\mathrm{CO}_{2}$ and $\mathrm{H}_{2} \mathrm{~S}^{15}$ Ammonia can be separated when the biogas is dried or upgraded. ${ }^{4}$ In the case of siloxanes, the most used removal method so far is adsorption on activated carbon. ${ }^{16}$ Moreover, solid adsorption has recently been investigated as a possibility for the joint elimination of $\mathrm{H}_{2} \mathrm{~S}$ and siloxanes. ${ }^{17}$ Thus biogas cleaning and upgrading constitute the key challenge of the biogas supply chain, and research efforts are conducted to reduce the high cost associated with this critical step.

Among the different bioenergy technologies that would allow the spread of biogas utilization, there is one that stands out because it allows the direct use of biogas without prior cleaning, with the significant energy and economic advantages that this implies. This technology is chemical looping combustion (CLC). Here the combustion is split into two reactors, commonly two fluidized beds, and the oxygen required for combustion is supplied by an oxygen carrier (metal oxide) that circulates between them. ${ }^{18}$ In the reduction reactor, the fuel is supplied and oxidized to $\mathrm{CO}_{2}$ and $\mathrm{H}_{2} \mathrm{O}$ while the oxygen carrier is reduced. In the oxidation reactor, the reduced oxygen carrier is reoxidized in air. Because the $\mathrm{CO}_{2}$ from combustion is in a highly concentrated form from the fuel reactor, the technology is highly applicable for carbon capture. If fuels of a biogenic nature are used in the process and carbon capture is employed, then it can result in the actual removal of $\mathrm{CO}_{2}$ from the atmosphere or negative emissions. ${ }^{19}$ This is based on the premise that biomass and plants can absorb $\mathrm{CO}_{2}$ through photosynthesis, and if the biomass is sustainably converted, then it will result in an actual flow of carbon out from the atmosphere. After more than 20 years of intensive research, this technology has reached a high level of development, ${ }^{20}$ and it currently stands at a technical readiness level (TRL) of 6 to $7 .^{21}$ However, most of the development work has been related to natural gas or solid fuels, such as coal and biomass, with very few studies exploring the use of biogas. No studies that specifically relate to the important fate of siloxanes in the gas have previously been conducted. Different oxygen carriers have been tested during these years, both synthetic and natural (minerals), mostly based on metal oxides (mainly $\mathrm{NiO}, \mathrm{CuO}, \mathrm{Mn}_{3} \mathrm{O}_{4}$, and $\mathrm{Fe}_{2} \mathrm{O}_{3}$ ) and mixed oxides obtained by a combination of the latter. ${ }^{22}$ The type of oxygen carrier used in a CLC system depends on the type of fuel to be burnt, and its selection influences the final cost of the process. ${ }^{23}$ In the combustion of gaseous fuels, highly reactive synthetic oxygen carriers are preferred, although their production cost is commonly high. ${ }^{24}$ In the combustion of solid fuels, low-cost oxygen carriers are a more adequate option because oxygen carrier losses are expected during the ash drainage step. In this case, minerals or industrial wastes/ residues are used.

Despite the experience gained in CLC of gaseous fuels, to date, few studies have addressed the possibility of burning biogas. Nevertheless, CLC has some features that could make it highly applicable for biogas. First, $\mathrm{CO}_{2}$ in the biogas does not need to be removed because it would be captured together with the $\mathrm{CO}_{2}$ produced during combustion. Moreover, there are available oxygen carriers with high reactivity to sour/acid gas and resistance to sulfur deactivation, which would avoid the need for previous $\mathrm{H}_{2} \mathrm{~S}$ removal. ${ }^{25}$ Specific studies about the fate of $\mathrm{NH}_{3}$ in coal CLC systems revealed that it was mostly converted to $\mathrm{N}_{2}$ in the fuel reactor. ${ }^{26}$ Thus the presence of $\mathrm{H}_{2} \mathrm{~S}$ and $\mathrm{NH}_{3}$ in biogas should not represent a problem. However, no specific studies on the effect of siloxanes on CLC performance have been addressed until now. It would be nevertheless expected that the formation of $\mathrm{SiO}_{2}$ during the combustion process may not affect the components of the CLC system to a large extent. Many oxygen carriers have been tested that contain $\mathrm{SiO}_{2}$, either as an inert carrier or included as an impurity in natural ores or wastes. Hence, any interaction between an oxygen carrier and $\mathrm{SiO}_{2}$ may not necessarily be detrimental to the combustion performance. In any case, it could affect the reactivity of the oxygen carrier used in the event of any interaction between the carrier and $\mathrm{SiO}_{2}$ under the conditions used for combustion. Still, if it is possible to find an oxygen carrier that is not detrimentally affected by the $\mathrm{Si}$, then CLC may be a very useful technique for converting biogas, as no or very limited pretreatment is needed. If the carbon is captured and stored, then negative emissions will also be achieved.

With all of these considerations, the objective of the present work was to analyze the possible effects of siloxanes in biogas 


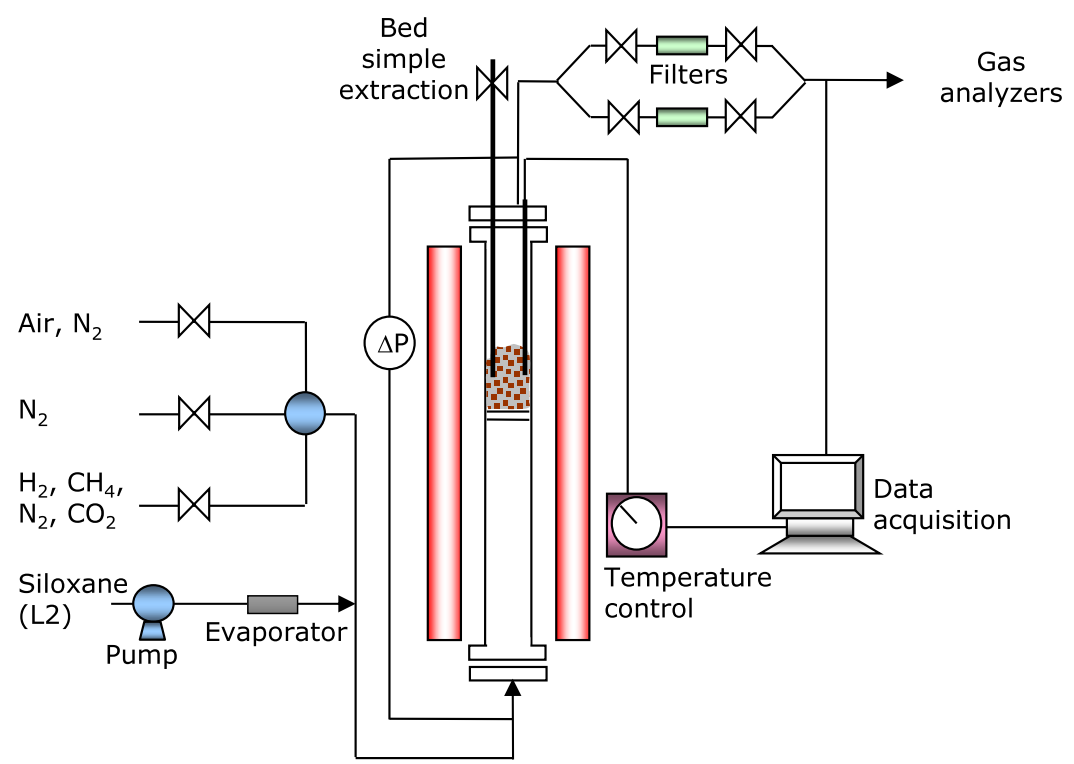

Figure 1. Scheme of the batch fluidized bed setup

CLC processes by studying the reactivity and physicochemical changes of selected oxygen carriers during combustion in a batch fluidized bed reactor. Two representative oxygen carriers based on $\mathrm{CuO}$ and $\mathrm{Fe}_{2} \mathrm{O}_{3}$ were chosen considering the high reactivity in the combustion of the methane of $\mathrm{Cu}$-based oxygen carriers and the resistance to sulfur deactivation that Fe-based oxygen carriers have shown.

\section{MATERIALS AND EXPERIMENTAL SETUP}

2.1. Materials. 2.1.1. Biogas Stream. All of the experiments performed in this work used a simulated biogas stream composed of methane and siloxane. This mixture is believed to give a good view of the behavior of siloxanes in a fuel reactor together with oxygen carriers. Methane is the major and least reactive of the main components of biogas. Other impurities, such as $\mathrm{H}_{2} \mathrm{~S}$, were not considered because an interaction between $\mathrm{H}_{2} \mathrm{~S}$ and the oxygen carriers used in this work is not expected. A siloxane model compound was added to the stream. Siloxanes are named considering the number of $\mathrm{Si}$ atoms in their molecular structure. The most commonly found siloxanes in biogas are hexamethyldisiloxane (L2), octamethyltrisiloxane (L3), decamethyltetrasiloxane (L4), dodecamethylpentasiloxane (L5), hexamethylcyclotrisiloxane (D3), octamethylcyclotetrasiloxane (D4), decamethylcyclopentasiloxane (D5), and dodecamethylcyclohexasiloxane (D6). 27,28 Among them, L2 $\left(\mathrm{C}_{6} \mathrm{H}_{18} \mathrm{OSi}_{2}\right)$ was selected to perform the experiments due its higher volatility and its abundant presence in biogas from landfills. ${ }^{9}$ L2 (solution 98 wt \%) supplied by Fisher Scientific was used in the experiments.

2.1.2. Oxygen Carriers. To study the possible deposition of silicon $(\mathrm{Si})$ on the oxygen carriers, it is necessary that they originally do not contain any significant fraction of $\mathrm{Si}$ in the structure. This is to not distort the analysis of the used oxygen carriers. Following this, one synthetic material based on $\mathrm{CuO}$ with a high reactivity to methane and an industrial residue based on $\mathrm{Fe}_{2} \mathrm{O}_{3}$ and resistant to sulfur deactivation were considered. The $\mathrm{CuO}$-based oxygen carrier used in this work (Cu14Al ICB) was prepared by the incipient wet impregnation method on a commercial $\gamma-\mathrm{Al}_{2} \mathrm{O}_{3}$ from Sasol with a particle size of $300-500 \mu \mathrm{m}$. The total impregnated $\mathrm{CuO}$ represented 14 wt \%. The oxygen carrier was then calcined at $850{ }^{\circ} \mathrm{C}$ for $1 \mathrm{~h}$. More details of the preparation of the oxygen carrier can be found elsewhere. ${ }^{29}$ The Fe-based industrial residue is identified by its commercial name, Promifer. This residue generated in the "Ruthner" process is a valuable byproduct because it is composed of $100 \%$ $\mathrm{Fe}_{2} \mathrm{O}_{3}$. Promifer was recently tested by the authors as a potential oxygen carrier for the CLC process. ${ }^{30}$ The sample used here was obtained by fluidized bed granulation in the $100-300 \mu \mathrm{m}$ size range and calcined at $1300{ }^{\circ} \mathrm{C}$ for $4 \mathrm{~h}$ prior to its use.

2.2. Experimental Setup and Methodology. The methodology used is based on a discontinuous fluidized bed installation where the operating conditions can be more easily varied and in a wider range than in continuous installations. Thus it is possible to reduce the experimentation time required to determine the possible effects of the presence of siloxanes. Figure 1 shows the scheme of the batch fluidized bed. Details of the reactor characteristics can be found elsewhere. $^{31}$

During the experiments, $300 \mathrm{~g}$ of the corresponding oxygen carrier wereloaded in the reactor. Then, the gaseous atmosphere was varied, alternating the reducing composition corresponding to that of the reduction reactor with the oxidant atmosphere corresponding to that found in the oxidation reactor. The operating conditions used in the experiments are shown in Table 2 . The gas velocity was set to $15 \mathrm{~cm} /$

Table 2. Experimental Conditions for the Redox Cycles in the Batch Fluidized Bed

\begin{tabular}{lccccccc} 
& & \multicolumn{3}{c}{ reduction } & & oxidation \\
\cline { 3 - 5 } oxygen carrier & $\begin{array}{c}T \\
\left({ }^{\circ} \mathrm{C}\right)\end{array}$ & $\begin{array}{c}{\left[\mathrm{CH}_{4}\right]} \\
(\mathrm{vol} \%)\end{array}$ & $\begin{array}{c}{[\mathrm{L} 2]} \\
(\mathrm{vol} \%)\end{array}$ & $\begin{array}{c}t_{\mathrm{R}} \\
(\mathrm{min})\end{array}$ & $\begin{array}{c}{\left[\mathrm{O}_{2}\right]} \\
(\mathrm{vol} \%)\end{array}$ & $\begin{array}{c}\text { number } \\
\text { of cycles }\end{array}$ \\
Cu14Al_ICB & 800 & 2.5 & 1.5 & 15 & 5 & 4 \\
Promifer & 950 & 25 & 1.5 & 15 & 10 & 4
\end{tabular}

$\mathrm{s}$ for both reduction and oxidation. During the reduction step, different methane concentrations and temperatures were used with the two oxygen carriers, which was due to their different reactivities. The temperatures selected were those under which the oxygen carriers performed better. In the case of Cu14Al_ICB, the methane concentration was $2.5 \mathrm{vol} \%$, and the temperature was $800{ }^{\circ} \mathrm{C}$ to avoid copper loss and to maintain suitable mechanical performance. ${ }^{32}$ In the case of Promifer, a 25 vol \% methane concentration was used, and the temperature was set to $950{ }^{\circ} \mathrm{C}$ because the reactivity with methane is low at $800^{\circ} \mathrm{C}$, as with other Fe-based oxygen carriers. In this case, the maximum reduction of the material was set to $\mathrm{Fe}_{3} \mathrm{O}_{4}$, similar to what is done in the combustion processes in continuous plants. ${ }^{33}$ It should also be mentioned that the Promifer sample used was previously activated to further increase its reactivity, as has been commonly done before with this type of oxygen carrier (minerals or residues). For that purpose, several redox cycles with $\mathrm{H}_{2}$ were performed. Hexamethyldisiloxane (L2) was fed into the reactor by means of a peristaltic 


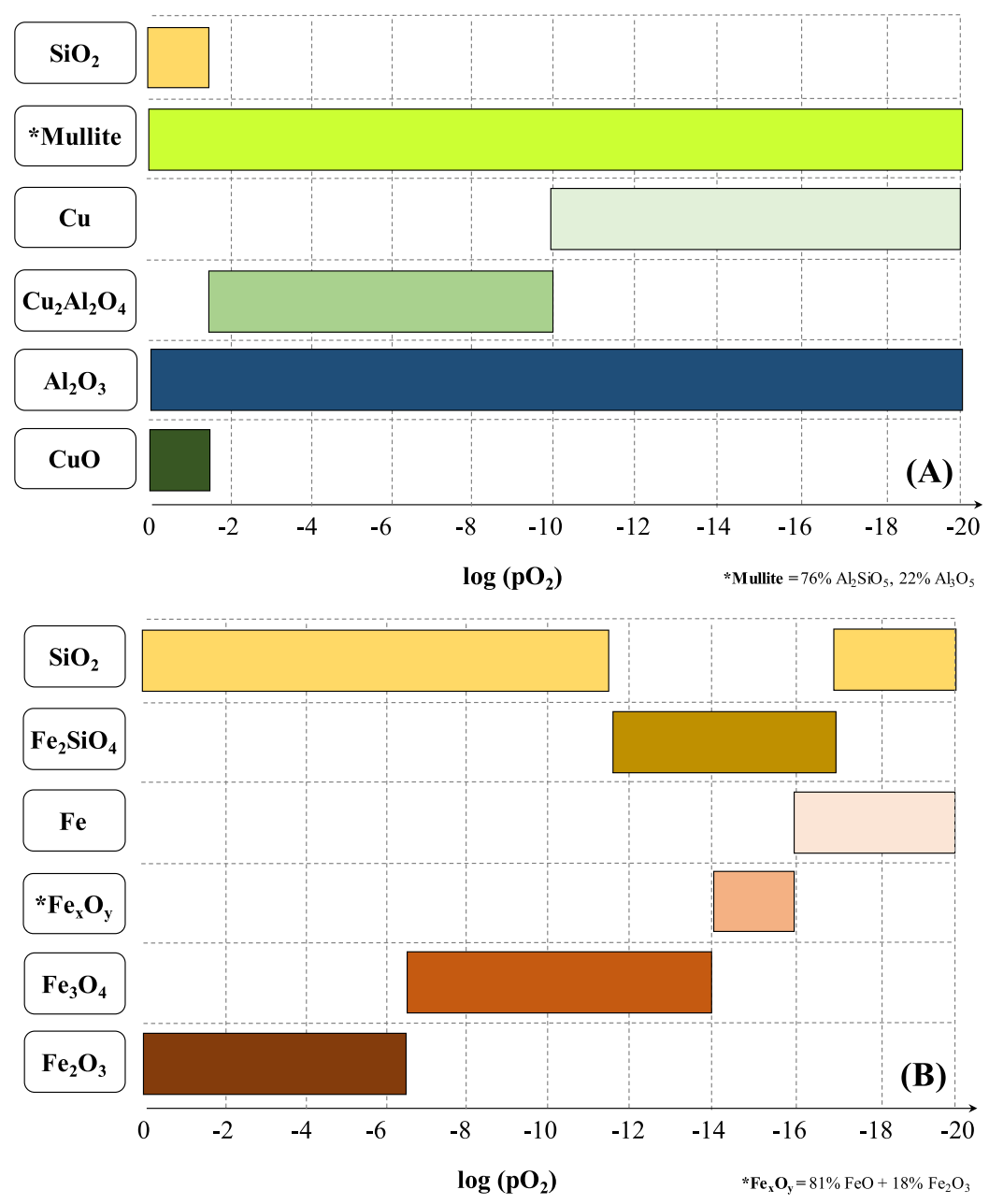

Figure 2. Stable solid phases as a function of the logarithm of the partial pressure of oxygen present in the gaseous atmosphere (A) Cu14Al_ICB at $800{ }^{\circ} \mathrm{C}$ and (B) Promifer at $950^{\circ} \mathrm{C}$.

pump that made it possible to regulate the flow of siloxane introduced followed by an evaporator. The reduction time was set to $15 \mathrm{~min}$ to facilitate the analysis of the influence of the presence of the siloxane. The amount of L2 introduced in each reduction cycle was much higher than that corresponding to a real biogas. In this way, the detection of possible effects derived from the presence of siloxanes was accelerated. To compare the results between oxygen carriers, we set the total amount of $\mathrm{Si}$ introduced with the siloxane during the cycles for both cases to $10.5 \mathrm{~g}$. The siloxane flow rate corresponded to the minimum possible rate that the peristaltic pump was able to provide. In this way, the siloxane concentration in the reduction gas was between 99000 and $113000 \mathrm{mg} / \mathrm{Nm}^{3}(\sim 1.5 \mathrm{vol} \%)$, much higher than the average values shown in Table 1.

During the oxidation step, diluted air $\left(5-10 \% \mathrm{O}_{2}\right.$ in nitrogen $)$ was used to limit the temperature increase in this stage. Under these conditions, four successive reduction-oxidation cycles were performed with each oxygen carrier, with nitrogen purges between reduction and oxidation to avoid the mixing of reactive atmospheres. During these purge periods, a small amount of sample was drawn from the bed in selected cycles so that its composition could then be analyzed.

Two filters at the reactor outlet retained the particles that may be present in the outlet gas stream. The gases were analyzed. The $\mathrm{H}_{2}$ measurement was based on the thermal conductivity. A nondispersive infrared (NDIR) analyzer measured $\mathrm{CH}_{4}, \mathrm{CO}$, and $\mathrm{CO}_{2}$. The oxygen concentration was determined using a paramagnetic analyzer. All data were collected with a data logger connected to a computer.

2.3. Characterization of the Samples Extracted from the Batch Reactor. During the successive redox cycles carried out with both oxygen carriers, samples in both reduced and oxidized states were taken from the bed during the purge periods. The samples were characterized by different techniques to investigate if the presence of hexamethyldisiloxane and its possible decomposition to $\mathrm{SiO}_{2}$ affected the oxygen carrier due to some type of deposition/interaction on the particles.

The composition of the used particles was determined using an inductively coupled plasma-optical emission spectrometry (ICPOES) Xpectroblue-EOP-TI FMT26 (Spectro) spectrophotometer. The oxidation state of samples was studied by XPS in an ESCAPlus Omicron spectrometer equipped with nonmonochromatized $\mathrm{Mg} \mathrm{K} \alpha$ radiation $(1253.6 \mathrm{eV})$. The hemispherical electron energy analyzer was operated at a pass energy of $50 \mathrm{eV}$ for surveys and $20 \mathrm{eV}$ for highresolution spectra. Binding energies (BEs) were referenced to the $\mathrm{C}$ $1 s$ peak $(284.5 \mathrm{eV})$ from adventitious carbon contamination. Current region sweeps for $\mathrm{O} 1 \mathrm{~s}, \mathrm{Fe} 2 \mathrm{p}, \mathrm{Cu} 2 \mathrm{p}$, and $\mathrm{Si} 2 \mathrm{p}$ were obtained. The computer-aided surface analysis (CASA) data-processing software ${ }^{34}$ allowed smoothing, background substration, peak fitting, and quantification. The identification of the crystalline chemical species in the samples was carried out by X-ray diffraction (XRD) in a Bruker D8 Advance A25 X-ray powder diffractometer equipped with an X-ray source with a $\mathrm{Cu}$ anode working at $40 \mathrm{kV}$ and $40 \mathrm{~mA}$ and an energydispersive $1 \mathrm{D}$ detector. The microstructure of the oxygen carrier material was explored through a scanning electron microscope (SEM) EDX Hitachi S-3400N equipped with an EDX analyzer Röntec XFlash of $\mathrm{Si}(\mathrm{Li})$. Finally, reactivity tests of fresh and used oxygen carriers were done in a thermogravimetric apparatus (TGA) (CI Electronics type) described elsewhere. ${ }^{35}$ 


\section{RESULTS AND DISCUSSION}

3.1. Theoretical Evaluation. A study of possible Si-based solid-phase formation as result of the interaction between siloxane and the oxygen carrier under the operating conditions in the batch fluidized bed reactor was accomplished to compare with the information obtained from the experiments. Thermodynamic equilibrium calculations were applied to determine the stable chemical and physical forms in the corresponding systems. The software FactSage ${ }^{36}$ was used for thermodynamic calculations. To increase the accuracy of the FACT databases included in the software, some species from HSC Chemistry ${ }^{37}$ and FACT were also included. The calculations were performed using the "Equilib" module in Factsage, and here the main components in the oxygen carriers were added in addition to the varying content of Si. It is expected that the siloxane will decompose in the fuel reactor and that $\mathrm{Si}$ or $\mathrm{SiO}_{2}$ will result, and hence it was believed that the $\mathrm{Fe}-\mathrm{Si}$ and $\mathrm{Cu}-\mathrm{Al}-\mathrm{Si}$ systems are relevant.

Figure 2 shows the stable solid phases in each oxygen carrier as a function of the logarithm of the partial pressure of oxygen present in the gaseous atmosphere, which can be correlated to reducing or oxidizing conditions through the calculation of the reduction potential and the $\mathrm{CO}_{2}$ yield $\left(\gamma_{\mathrm{CO}_{2}}\right)$. The reduction potential is expressed as the logarithmic ratio of $\mathrm{CO}$ and $\mathrm{CO}_{2}$ partial pressures $\left(\mathrm{pCO} / \mathrm{pCO}_{2}\right)$ following the reaction $\mathrm{CO}+1 / 2 \mathrm{O}_{2} \rightarrow \mathrm{CO}_{2}$, whereas the $\mathrm{CO}_{2}$ yield represents the quotient $\mathrm{pCO}_{2} /\left(\mathrm{pCO}+\mathrm{pCO}_{2}\right)$. The relation under the corresponding operating conditions is shown in Table 3 for

Table 3. Relation between Oxygen Partial Pressure in Figure 2, Reduction Potential, and $\mathrm{CO}_{2}$ Yield for $\mathrm{Cu} 14 \mathrm{Al}$ ICB at $800{ }^{\circ} \mathrm{C}$ and Promifer at $950{ }^{\circ} \mathrm{C}$

\begin{tabular}{|c|c|c|c|}
\hline $\begin{array}{l}\text { oxygen partial } \\
\text { pressure }\left(\log _{10}\left[\mathrm{pO}_{2}\right]\right)\end{array}$ & $\begin{array}{l}\text { reduction potential } \\
\left(\log _{10}\left[\mathrm{pCO} / \mathrm{pCO}_{2}\right]\right)\end{array}$ & condition & $\begin{array}{c}\mathrm{CO}_{2} \text { yield } \\
\left(\gamma_{\mathrm{CO}_{2}}\right)\end{array}$ \\
\hline \multicolumn{4}{|c|}{$\mathrm{Cu} 14 \mathrm{Al}$ ICB $\left(800{ }^{\circ} \mathrm{C}\right)$} \\
\hline-1.5 & -8.5 & oxidizing & 1.0000 \\
\hline-10 & -4.2 & $\begin{array}{l}\text { moderately } \\
\text { reducing }\end{array}$ & 0.9999 \\
\hline-20 & 0.8 & $\begin{array}{l}\text { highly } \\
\text { reducing }\end{array}$ & 0.1405 \\
\hline \multicolumn{4}{|c|}{ Promifer $\left(950{ }^{\circ} \mathrm{C}\right)$} \\
\hline-6.5 & -4.3 & oxidizing & $>0.9999$ \\
\hline-11.5 & -1.8 & $\begin{array}{l}\text { moderately } \\
\text { reducing }\end{array}$ & 0.9836 \\
\hline-14 & -0.5 & \multirow{4}{*}{$\begin{array}{l}\text { highly } \\
\text { reducing }\end{array}$} & 0.7710 \\
\hline-16 & 0.5 & & 0.2519 \\
\hline-17 & 1.0 & & 0.0962 \\
\hline-20 & 2.5 & & 0.0034 \\
\hline
\end{tabular}

both oxygen carriers. In the case of $\mathrm{Cu} 14 \mathrm{Al}$ ICB in Figure 2A, results were obtained for a constant temperature of $800{ }^{\circ} \mathrm{C}$. According to the calculations, the $\mathrm{Si}$ in the siloxane may be found in the oxygen carrier as $\mathrm{SiO}_{2}$ for $\log _{10}\left(\mathrm{pO}_{2}\right)$ up to -1.5 , that is, oxidizing conditions, or as aluminosilicates (mullite) under the rest of the conditions. From the calculations, it seems that there are no stable $\mathrm{Cu}-\mathrm{Si}$ compounds. In the case of the Promifer oxygen carrier in Figure $2 \mathrm{~B}$, the results correspond to a constant temperature of $950{ }^{\circ} \mathrm{C}$. The $\mathrm{Si}$ in the siloxane may also interact with the oxygen carrier, but the resulting species may depend on the reaction conditions. In the transformation of $\mathrm{Fe}_{2} \mathrm{O}_{3}$ to $\mathrm{Fe}_{3} \mathrm{O}_{4}$ up to $\log _{10}\left(\mathrm{pO}_{2}\right)-6.5$ (oxidizing conditions), which is the desired for CLC operation of the oxygen carrier, the $\mathrm{Si}$ in the siloxane may appear as $\mathrm{SiO}_{2}$ on the oxygen carrier. If the reduction of $\mathrm{Fe}_{3} \mathrm{O}_{4}$ further proceeds to $\log _{10}\left(\mathrm{pO}_{2}\right)-11.5$, that is, moderate reducing conditions, then the formation of silicates $\left(\mathrm{Fe}_{2} \mathrm{SiO}_{4}\right)$ is favored instead. Finally, when elemental iron $(\mathrm{Fe})$ is the main iron species under high reducing conditions at $\log _{10}\left(\mathrm{pO}_{2}\right)-16$, then $\mathrm{Si}$ may be present again as $\mathrm{SiO}_{2}$.

3.2. Batch Fluidized Bed Results. 3.2.1. Siloxane Decomposition and Reaction with the Oxygen Carrier. Former studies about siloxane thermal degradation indicated that this type of compounds decomposes to mostly $\mathrm{H}_{2}$ and $\mathrm{CH}_{4}$ at temperatures of $\sim 800{ }^{\circ} \mathrm{C} .^{38-40}$ Silica formation from hexamethyldisiloxane (L2) oxidation was also reported in the postcombustion gases of $\mathrm{CH}_{4}-\mathrm{N}_{2} /$ air diffusion flames. The initial size of the final silica particles was estimated as $10 \mathrm{~nm}^{41}$ Considering this, preliminary experiments were carried out to investigate the behavior of hexamethyldisiloxane (L2) under CLC conditions, especially product distribution at the batch reactor outlet. Figure 3 shows the corresponding results using Promifer at $950{ }^{\circ} \mathrm{C}$ and feeding only siloxane (1.5 vol \% in nitrogen) during reduction and oxidizing with diluted air. The oxygen carrier conversion $\left(X_{\mathrm{s}}\right)$ is shown together with the product distribution, and it is defined as

$$
X_{\mathrm{s}}=\frac{\left|m-m_{\mathrm{red}}\right|}{m_{\mathrm{ox}}-m_{\mathrm{red}}}
$$

where $m$ is the mass of the oxygen carrier in the bed and $m_{\text {red }}$ and $m_{\text {oxi }}$ are the masses of the totally reduced and oxidized samples, respectively. Details of the calculation of oxygen carrier conversion can be found elsewhere. ${ }^{31}$

It was found that once introduced into the reactor at the corresponding temperature, the hexamethyldisiloxane decomposes, and the resulting products are able to react with the oxygen carrier to some extent, depending on the reactivity of the oxygen carrier. It should be indicated here that the reactivity to methane of this sample of Promifer was not especially high because it had to be calcined at a very high temperature $\left(1300{ }^{\circ} \mathrm{C}\right)$ to reach enough mechanical strength to be used in the fluidized bed. The gaseous fraction (vol \%) detected at the outlet of the reactor mainly consisted of $\mathrm{CH}_{4}$ $(\sim 1.9 \%), \mathrm{CO}(\sim 0.9 \%), \mathrm{H}_{2}(\sim 1.6 \%)$, and $\mathrm{CO}_{2}(\sim 0.25 \%)$. In addition to the gases shown in the figure, $\sim 2$ vol \% (averaged) $\mathrm{C}_{2} \mathrm{H}_{6} / \mathrm{C}_{2} \mathrm{H}_{4}$ was determined in a GC CLARUS 580 apparatus using sample bags and a flame ionization detector (FID) detector. During the oxidation period, $\mathrm{CO} / \mathrm{CO}_{2}$ was detected once diluted air was introduced to the reactor, indicating the formation of a carbon deposit on the oxygen carrier as a result of hexamethyldisiloxane pyrolysis. It is also remarkable that during this experiment, a significant number of particles were retained in the filters at the outlet of the reactor. Further analysis of this sample was conducted by ICP-OES and scanning electron microscopy-energy-dispersive X-ray spectroscopy (SEM-EDX), and they confirmed the existence of $\mathrm{SiO}_{2}$ particles in the fines, as was expected from siloxane decomposition.

3.2.2. Experiments with Simulated Biogas Stream. Experiments with a simulated biogas stream during the reduction period, that is, with methane and hexamethyldisiloxane (L2), were carried out for both $\mathrm{Cu} 14 \mathrm{Al}$ ICB and Promifer oxygen carriers. From these experiments, information about the gas product distribution at the batch reactor outlet and the formation of fine particles can be obtained. Figure 4 depicts the 


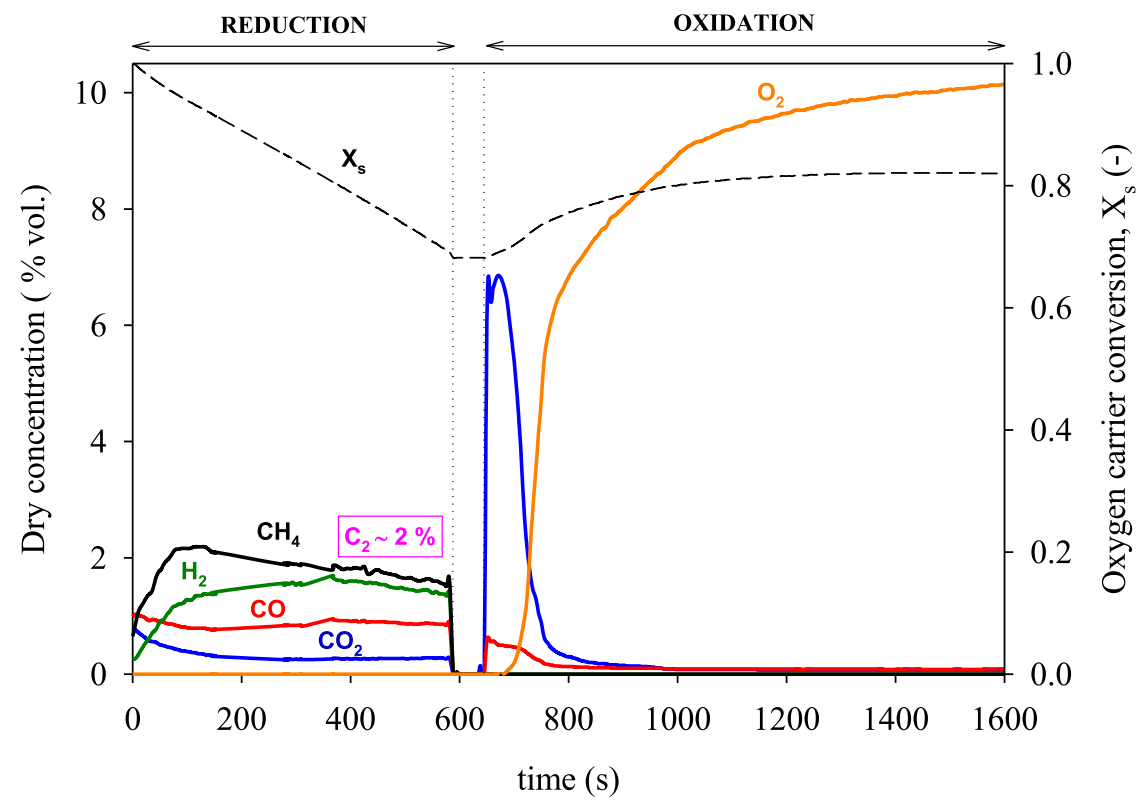

Figure 3. Gaseous products and oxygen carrier conversion $\left(X_{\mathrm{s}}\right)$ in experiments with Promifer feeding $\mathrm{L} 2\left(950{ }^{\circ} \mathrm{C}\right)$.
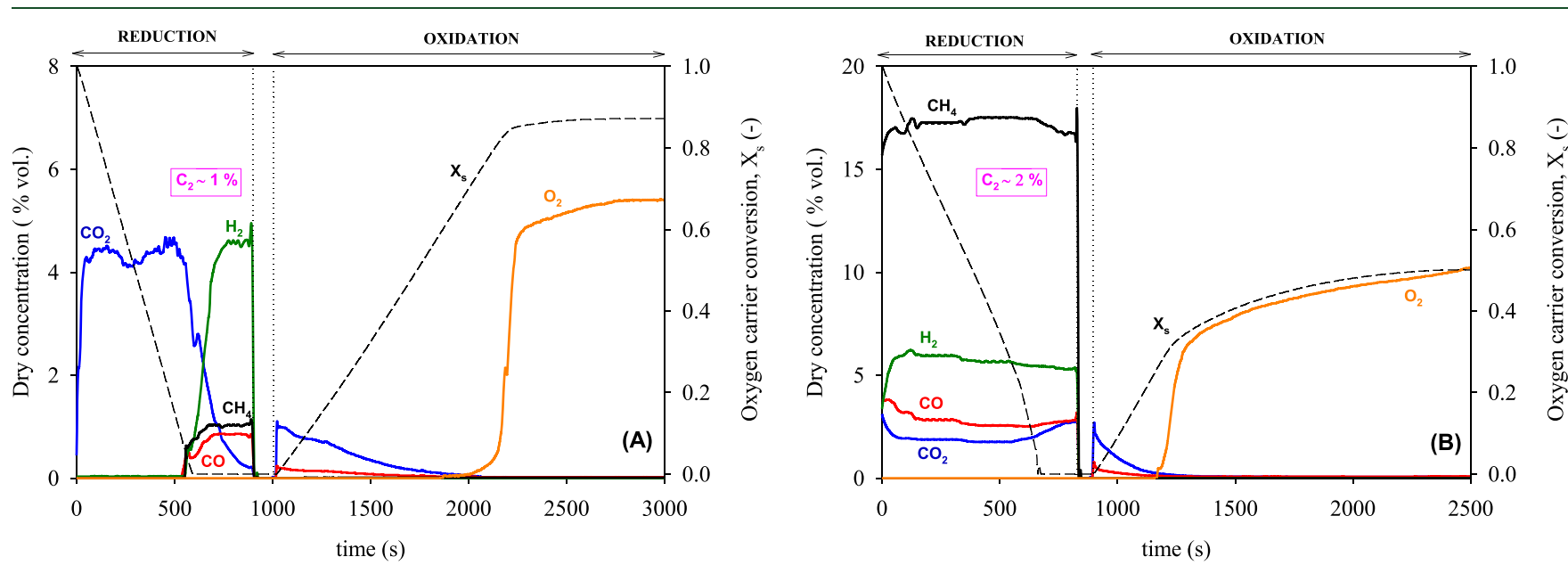

Figure 4. Gas product distribution and oxygen carrier conversion $\left(X_{\mathrm{s}}\right)$ evolution for (A) Cu14Al_ICB and (B) Promifer in the fourth redox cycle under conditions shown in Table 2.

product gas distribution and oxygen carrier conversion for the fourth redox cycle with both oxygen carriers. Two periods can be observed during the reduction step in the corresponding cycle performed with Cu14Al_ICB in Figure 4A. During the first period, only $\mathrm{CO}_{2}$ was detected as a gaseous product. This reflects the high reactivity of $\mathrm{Cu} 14 \mathrm{Al}$ ICB, which was able to burn both the methane and $\mathrm{H}_{2}$ that resulted from the decomposition of siloxane. The second period corresponds to a high conversion of the oxygen carrier and thus to a lower availability of oxygen in the bed. In this period, incomplete combustion is observed because $\mathrm{CH}_{4} / \mathrm{C}_{2}, \mathrm{CO}$, and $\mathrm{H}_{2}$ are detected at the reactor outlet. During the oxidation period, $\mathrm{CO} / \mathrm{CO}_{2}$ were detected, indicating that carbon deposition took place during the reduction period. This carbon formation may be attributed to both methane and hexamethyldisiloxane decomposition, although it is not easy to determine the contribution of each species with the current experimental methodology. Nevertheless, it should be noted that despite the carbon formation, fluidization was not affected.
In the case of Promifer in Figure 4B, the reactivity of the oxygen carrier was lower, and the complete combustion of methane was not reached, as $\mathrm{CH}_{4} / \mathrm{C}_{2}$ and $\mathrm{CO}$ were present together with some $\mathrm{CO}_{2}$ in the reducing period. Some $\mathrm{H}_{2}$ was also detected, which could have been produced during hexamethyldisiloxane decomposition but does not completely react with the oxygen carrier. As was the case with the copperbased oxygen carrier, carbon formation during reduction was also confirmed by $\mathrm{CO} / \mathrm{CO}_{2}$ detection during the first stages of oxidation. But again, no defluidization problems were observed.

Filters at the outlet of the reactor were periodically checked. Almost no particles were found during the experiments with Cu14Al_ICB. That was expected because the attrition of the material under those experimental conditions was not high. ${ }^{32}$ During the experiments with Promifer, a higher attrition was observed, similar to what was found with the reference experiments with $\mathrm{L} 2$.

3.3. Analysis of the Interaction between Oxygen Carrier and Siloxane. During the experiments in the batch 
Table 4. XPS Quantification for the Cu14A_ICB and Promifer Samples in Reduced and Oxidized State Extracted during the Fourth Cycle in the Batch Reactor

\begin{tabular}{|c|c|c|c|c|c|c|c|c|c|c|}
\hline & \multicolumn{5}{|c|}{ at $\%$} & \multicolumn{5}{|c|}{ wt $\%$} \\
\hline & $\mathrm{O}$ & $\mathrm{Cu}$ & $\mathrm{Al}$ & $\mathrm{Fe}$ & $\mathrm{Si}$ & $\mathrm{O}$ & $\mathrm{Cu}$ & $\mathrm{Al}$ & $\mathrm{Fe}$ & $\mathrm{Si}$ \\
\hline Cu14-fresh & 73.6 & 7.8 & 18.7 & & & 35.9 & 15.1 & 49.0 & & \\
\hline Cu14-oxi & 48.8 & 2.4 & 29.6 & & 19.2 & 34.4 & 6.7 & 35.2 & & 23.7 \\
\hline Cu14-red & 43.7 & 0.8 & 35.2 & & 20.3 & 30.8 & 2.2 & 41.8 & & 25.1 \\
\hline Pro-fresh & 65.5 & & & 34.5 & & 13.1 & & & 86.9 & \\
\hline Pro-oxi & 53.1 & & & 4.1 & 42.8 & 37.2 & & & 10.0 & 52.7 \\
\hline Pro-red & 50.5 & & & 3.8 & 45.7 & 34.8 & & & 9.2 & 55.9 \\
\hline
\end{tabular}
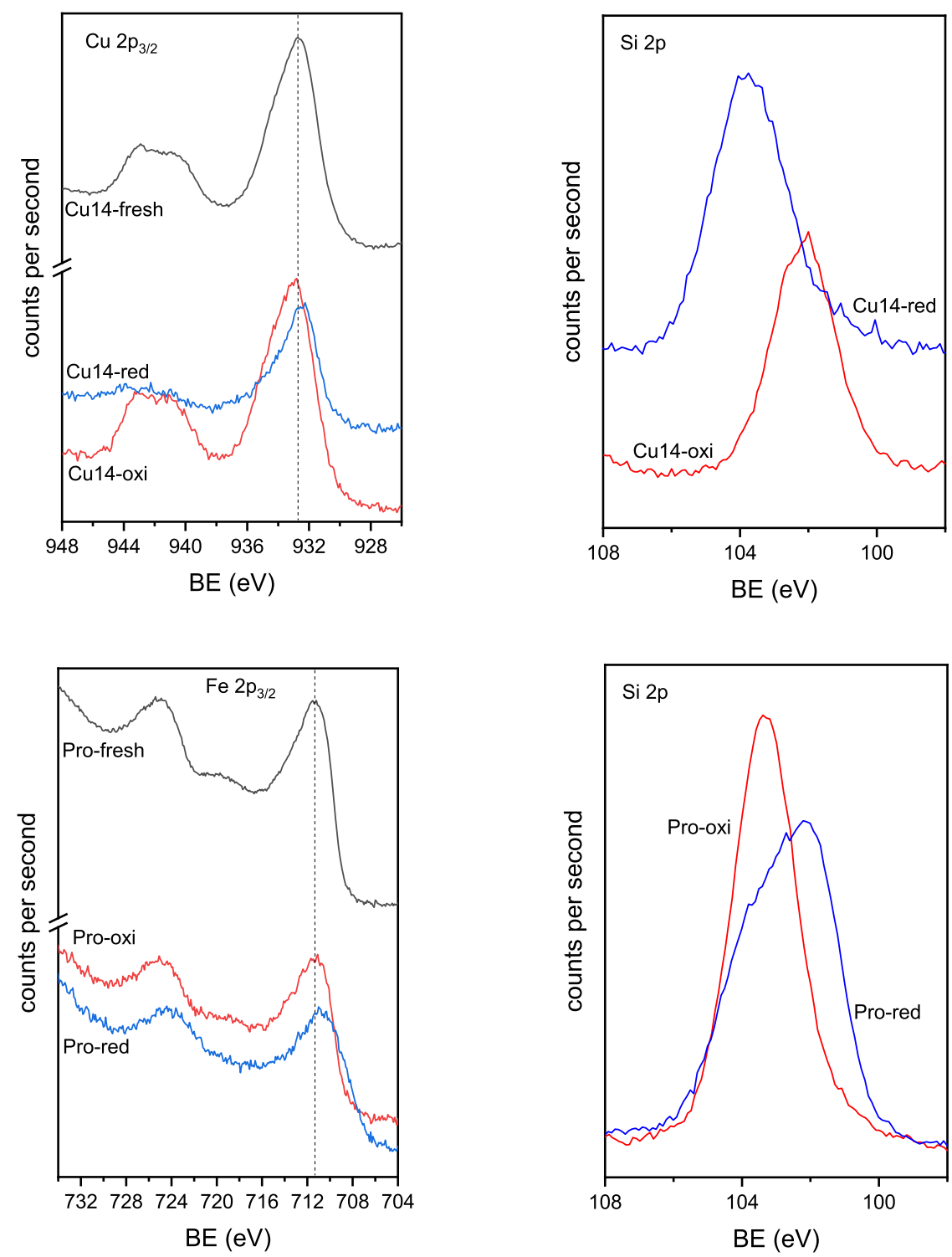

Figure 5. XPS spectra of different regions for Cu14Al_ICB and Promifer samples.

fluidized bed reactor, samples corresponding to reduced and oxidized oxygen carrier were extracted in each cycle and further characterized. First, the samples recovered in the oxidation of the fourth redox cycle were analyzed by ICP-OES to investigate their $\mathrm{Si}$ content. Si was found in both oxygen carriers after the experiments, whereas it was not present in the original particles. The total content of $\mathrm{Si}$ in the samples after the full reaction sequence represented 1 and 0.4 wt \% for Cu14Al_ICB and Promifer, respectively. This was the first indication of a possible interaction of the $\mathrm{SiO}_{2}$ resulting from L2 decomposition with the oxygen carrier. The amount of Si found in the oxygen carrier particles represents 31.5 (in the case of Cu14Al_ICB) and 10.3\% (in the case of Promifer) of the total $\mathrm{Si}$ introduced with the siloxane, which in both cases was $10.5 \mathrm{~g}$. Once the presence of $\mathrm{Si}$ in the oxygen carrier was confirmed, the investigation was focused on the type of interaction of the $\mathrm{Si}$ with the oxygen carrier material. With that purpose, X-ray photoelectron spectroscopy (XPS), SEM-EDX, 
$\mathrm{XRD}$, and thermogravimetric analyses were carried out on the used samples.

3.3.1. X-ray Photoelectron Spectroscopy. Elemental quantification resulting from the XPS analysis for fresh and both reduced and oxidized samples from the fourth cycle is shown in Table 4. The high content of Si found in the used samples compared with that provided by the ICP-OES analysis is noteworthy. This fact can be explained in terms of all of the Si present on the surface of the oxygen carrier covering either $\mathrm{Cu}$ or Fe. Figure 5 shows the $\mathrm{Cu} 2 \mathrm{p}_{2 / 3}$ XPS spectra of the Cu14Al_ICB oxygen carrier. The main peak was observed at BEs of $\overline{929-937 ~ e V, ~ a n d ~ t h e ~ s a t e l l i t e ~ p e a k ~ a p p e a r e d ~ a t ~ 938-~}$ $946 \mathrm{eV}$. The strong satellite of the fresh and oxidized sample is attributed to the highly oxidized state of the samples. However, in the reduced sample, the main peak is shifted to a lower BE, indicating the lower contribution of $\mathrm{Cu}$ oxidized species, as expected due to the reducing atmosphere; accordingly, the intensity of the satellite has dramatically decreased. The figure also shows the Fe 2p XPS spectra of the corresponding samples from Promifer. A core-level $2 \mathrm{p}_{2 / 3}$ peak is found around $711 \mathrm{eV}$ for the fresh and oxidized samples, indicating that most of the iron is present as $\mathrm{Fe}^{3+}$. A core-level $2 \mathrm{p}_{2 / 3}$ peak is found around $710 \mathrm{eV}$ for the reduced sample, indicating the presence of $\mathrm{Fe}^{2+}$ species. Tables S1 and S2 in the Supporting Information show the curve fitting of the XPS spectra. The results of the $\mathrm{Cu}$ and $\mathrm{Fe}$ species confirm that the $\mathrm{BE}$ shifts to lower values for reduced samples.

The Si 2p XPS spectra of the Cu14Al_ICB and Promifer oxygen carriers are also analyzed in Figure 5, and the curve fitting of the Si $2 p$ peak results is reported in Table 5. In all

Table 5. Si 2p Region Curve Fitting (BE in eV, Area in \%)

\begin{tabular}{lccccc} 
& \multicolumn{5}{c}{ Si 2p } \\
\cline { 2 - 3 } \cline { 5 - 6 } \cline { 5 - 6 } & \multicolumn{2}{c}{ silicates/alumino silicates } & & \multicolumn{2}{c}{ silica } \\
\cline { 2 - 3 } \cline { 5 - 6 } Cu14-oxi & 102.1 & 100.0 & & & area \\
Cu14-red & 102.9 & 34.3 & & 103.9 & 65.7 \\
Pro-oxi & 102.9 & 59.4 & & 103.8 & 40.6 \\
Pro-red & 102.1 & 61.0 & & 103.8 & 39.0 \\
\hline
\end{tabular}

cases, there is an important contribution of $\mathrm{Si}$ bonding in silicates and, in the case of Cu14Al_ICB, aluminosilicates, which cannot be differentiated by this technique, although kyanite, sillimarite and mullite are the most probable according to the BE. Except for the Cu14Al_ICB oxidized sample, a BE of $\sim 103.8 \mathrm{eV}$ can be assigned to the presence of silica $\left(\mathrm{SiO}_{2}\right)$. These results are in agreement with those presented in Figure 2 , corresponding to thermodynamic calculations that predicted the existence of $\mathrm{SiO}_{2}$ in both oxygen carriers and aluminosilicates in the Cu14Al_ICB sample. The formation of iron silicates was also observe $\bar{d}$ by XPS linked to the fraction of the $\mathrm{Fe}_{3} \mathrm{O}_{4}$ in the sample that could have started the transformation to $\mathrm{FeO}$.

3.3.2. Energy Dispersion X-ray Fluorescence Analysis. EDX coupled to SEM was used to confirm the presence of $\mathrm{Si}$ on the surface of the particles. This was more clearly observed with the Cu14Al_ICB sample because the amount of Si from the siloxane retained was higher than that in the case of the Promifer sample. Figure 6 shows SEM images of the sample, where evidently, an increase in the Si content on the surface of

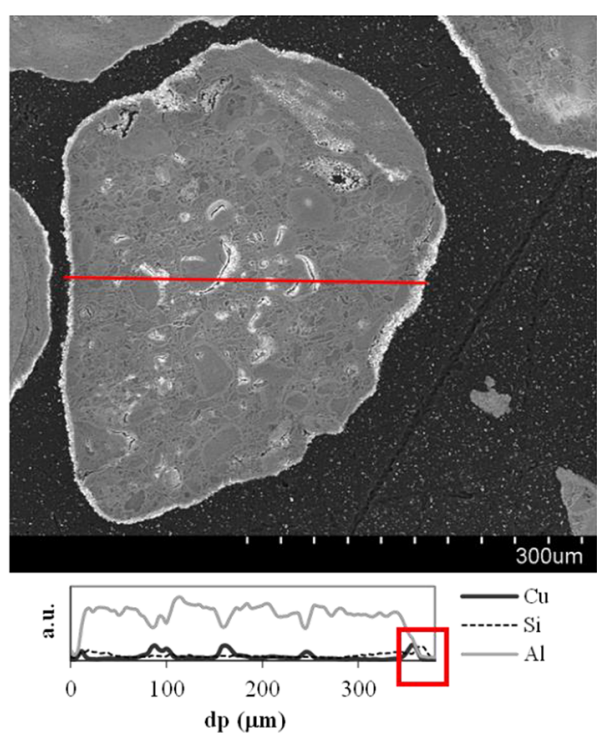

Figure 6. SEM images of the Cu14Al_ICB sample after the fourth redox cycle.

the particle can be observed together with an increase in the $\mathrm{Cu}$ attributed to the already known copper migration. ${ }^{32}$

To determine the nature of the silicates/aluminosilicates formed, we analyzed oxidized samples of the materials by $\mathrm{XRD}$; however, it was not possible to differentiate Sicontaining crystal phases through this technique because of the low $\mathrm{Si}$ bulk content of the samples. Nevertheless, the $\mathrm{SiO}_{2}$ deposition or silicate/aluminosilicate formation on the surface of oxygen carriers determined through the previous analyses can lead to changes in their reactivity. This was investigated in the TGA.

3.3.3. Reactivity in TGA. To investigate how Si deposition on the surface of the oxygen carrier particles affects their reactivity, experiments were performed in the TGA with oxidized samples of Cu14Al_ICB and Promifer after each of the cycles in the batch reactor. The reactivity was compared with that of fresh samples that had not been exposed to siloxanes. In the experiments, $15 \% \mathrm{CH}_{4}+20 \% \mathrm{H}_{2} \mathrm{O}$ was used during the reduction period and air during oxidation at temperatures equal to $800{ }^{\circ} \mathrm{C}$ in the case of Cu14Al_ICB and $950{ }^{\circ} \mathrm{C}$ in the case of Promifer. In all cases, the value of the rate index was obtained to analyze the possible changes in the reactivity through the cycles. The rate index is a normalized reaction rate, expressed in $\% / \mathrm{min}$, and is defined as

$$
\text { rate index }(\mathrm{RI})=100 \cdot 60 \cdot R_{\mathrm{OC}} \cdot\left(\frac{\mathrm{d} X_{i}}{\mathrm{~d} t}\right)_{\text {norm }}
$$

where $R_{\mathrm{OC}}$ is the oxygen transport capacity of the material ( $\mathrm{g}$ oxygen/g material) and $X_{i}$ is the conversion for reduction or oxidation. The normalized reactivity is calculated as

$$
\left(\frac{\mathrm{d} X_{i}}{\mathrm{~d} t}\right)_{\text {norm }}=\frac{p_{\mathrm{ref}}}{p_{\mathrm{TGA}}} \cdot\left(\frac{\mathrm{d} X_{i}}{\mathrm{~d} t}\right)
$$

where $p_{\text {ref }}$ is the reference partial pressure of the fuel gas $(0.15$ atm) and $p_{\mathrm{TGA}}$ is the partial pressure of the gas used in the TGA experiments. The rate $\left(\mathrm{d} X_{i} / \mathrm{d} t\right)$ was extrapolated during the first part of the reduction, where it can be expected that the surface reaction will be prevalent. 
Table 6. Normalized Reaction Rate and Corresponding Rate Index for the Successive Redox Cycles Performed with Cu14Al_ICB and Promifer ${ }^{a}$

\begin{tabular}{|c|c|c|c|c|c|}
\hline & original & cycle 1 & cycle2 & cycle 3 & cycle 4 \\
\hline \multicolumn{6}{|c|}{ Cu14Al_ICB } \\
\hline$\left(\mathrm{d} X_{i} / \mathrm{d} t\right)_{\text {norm }}\left(\mathrm{s}^{-1}\right)$ & 0.0757 & 0.0767 & 0.0674 & 0.074 & 0.0531 \\
\hline $\mathrm{RI}(\% / \mathrm{min})$ & 13.35 & 13.53 & 11.89 & 13.05 & 9.37 \\
\hline \multicolumn{6}{|c|}{ Promifer } \\
\hline$\left(\mathrm{d} X_{i} / \mathrm{d} t\right)_{\text {norm }}\left(\mathrm{s}^{-1}\right)$ & 0.029 & 0.022 & & 0.0143 & 0.0263 \\
\hline RI (\%/min) & 5.92 & 4.49 & & 2.92 & 5.37 \\
\hline
\end{tabular}

Table 6 presents the normalized reaction rates obtained for the samples for cycles 1 to 4 in the batch reactor and also the original sample. As can be seen, similar values of the normalized rate/rate index are obtained for the samples from different cycles, and these values are also similar to those found for the original sample. The standard deviation for the values obtained was calculated so that the average rate indexes could be expressed as $12.9 \pm 0.6$ and $5.2 \pm 0.5 \% / \mathrm{min}$ for Cu14Al_ICB and Promifer, respectively. According to these findings, it can be said that no significant changes are found in the reactivity of the oxygen carriers after Si deposition on their surface due to the interaction with L2 siloxane. This is correlated with the limited change in the BET surface area and porosity found in the particles extracted after the fourth cycle, as shown in Table 7 .

Table 7. BET Surface Area and Porosity of the Samples Extracted after the Fourth Cycle

\begin{tabular}{cccccc} 
& \multicolumn{2}{c}{ Cu14Al_ICB } & & \multicolumn{2}{c}{ Promifer } \\
\cline { 2 - 3 } \cline { 5 - 6 } fresh & $S_{\mathrm{g}}\left(\mathrm{m}^{2} / \mathrm{g}\right)$ & porosity $(\%)$ & & $S_{\mathrm{g}}\left(\mathrm{m}^{2} / \mathrm{g}\right)$ & porosity $(\%)$ \\
used & 91.3 & 50 & & 0.1 & 66 \\
& 63 & 42.1 & & 0.3 & 48
\end{tabular}

3.4. Discussion. Chemical looping could be an efficient technology for converting biogas fuels, as no or very little pretreatment of the gas will be needed. This is the first study of the impurity siloxane under relevant CLC conditions using $\mathrm{Cu}$ and Fe-based oxygen carriers. The study in the batch fluidized reactor shows that the presence of hexamethyldisiloxane (L2) affects the oxygen carrier primarily through the deposition of $\mathrm{Si}$ on the oxygen carrier material. In general, $\mathrm{Si}$ is a common component in oxygen carrier materials, ${ }^{20}$ and it can be speculated that any deposition could have both negative and positive implications. The $\mathrm{SiO}_{2}$ particles resulting from siloxane decomposition seem to interact on the surface of both Cu14Al_ICB and Promifer. Although experiments were conducted for a limited time, there was no major observable decrease in the oxygen carrier reactivity and thus in the performance of the biogas CLC combustion. Recent findings from the field of biomass ash interactions with bed materials in fluidized beds revealed that the presence of $\mathrm{K}$ together with $\mathrm{SiO}_{2}$ can lead to the formation of low-melting K-rich silicates ${ }^{42}$ that may favor agglomeration of particles. ${ }^{43}$ This was never the case in the experiments performed in this work, as no other reactive ash components are present in the biogas, but it could be a factor for other oxygen carriers, especially low-cost materials with some presence of K-based compounds in their composition. ${ }^{44}$ However, considering the small amounts of $\mathrm{K}$ and $\mathrm{Si}$ that would be involved, the possibility of encountering agglomeration problems is rather small.
It should be noted that the amounts of siloxane introduced to the batch reactor in the present study were at least three orders of magnitude higher than those that can be found in a real biogas. For a better comparison to real conditions, a rough estimation of the $\mathrm{Si}$ deposition from siloxanes could be done for the case of the well-known Cu14Al_ICB oxygen carrier, and this will be done as follows. For this oxygen carrier, a lifetime of $2500 \mathrm{~h}$ was reported during the combustion of methane in a continuous CLC unit. ${ }^{45}$ Calculations were done considering a $5 \mathrm{MW}$ CLC unit running on biogas. A total solids inventory of $750 \mathrm{~kg} / \mathrm{MW}$ was also assumed to ensure high combustion efficiency. ${ }^{46}$ An average value for the lower heating value of biogas of $6.5 \mathrm{kWh} / \mathrm{Nm}^{3}$ was considered in the calculation. ${ }^{4}$ It was also assumed that $\mathrm{L} 2$ was the main siloxane in biogas and that the maximum amount is that referenced in Table 1 for linear siloxanes $\left(15.2 \mathrm{mg} / \mathrm{Nm}^{3}\right)$. Under those conditions, the $\mathrm{Si}$ concentration on the $\mathrm{Cu} 14 \mathrm{Al}$ ICB oxygen carrier that would be reached, assuming that all $\mathrm{Si}$ in the siloxane was retained in the oxygen carrier, would be $0.25 \mathrm{wt}$ $\%$, lower than that observed under the batch fluidized bed experiments. Therefore, it is not expected that major problems would occur with respect to the fluidization or deactivation of the Cu14Al_ICB oxygen carrier in a continuous combustion CLC unit operated with real concentrations of siloxane. Actually, not only those oxygen carriers tested in this work but also most oxygen carriers will likely react with or absorb the $\mathrm{SiO}_{2}$ to stable phases. Hence, if there is no major deactivation with respect to the reactivity, then it can be expected that the oxygen carrier could act as a sink of $\mathrm{Si}$, which would be highly interesting because the normal problems encountered during biogas combustion may not be applicable. It also opens up the possibility for treating biogas with chemical-looping reforming technologies.

\section{CONCLUSIONS}

Siloxanes are an important impurity in biogas, which can have detrimental effects on heat exchangers and turbines. CLC of biogas could be an efficient way to achieve $\mathrm{CO}_{2}$ negative emissions. CLC can be of interest for the combustion of this type of gas because the $\mathrm{Si}$ in the biogas may not have negative implications on the oxygen carrier. To test this, we investigated CLC of methane and a common siloxane using a batch fluidized bed reactor. A model siloxane compound (hexamethyldisiloxane, L2) and two different oxygen carriers, namely, a synthetic material composed of $\mathrm{CuO}$ supported on alumina and a low-cost residue composed of $100 \% \mathrm{Fe}_{2} \mathrm{O}_{3}$, were investigated

It was found that siloxane decomposes to produce a gaseous fraction and Si-based particles that interact with the oxygen carrier. Part of the $\mathrm{Si}$ in these particles is found in the oxygen carrier (31.5 and $10.3 \%$ of the $\mathrm{Si}$ in siloxane for the $\mathrm{CuO}$ - and 
the $\mathrm{Fe}_{2} \mathrm{O}_{3}$-based oxygen carriers, respectively) and concentrated in the surface of the oxygen carrier particles in the form of $\mathrm{SiO}_{2}$ and silicates/aluminosilicates. This may have some implications for the reactivity of the carriers and their fluidization properties; however, no operation problems would be expected for the oxygen carriers tested in this work in a continuous combustion CLC unit operated with real concentrations of siloxane.

\section{ASSOCIATED CONTENT}

\section{SI Supporting Information}

The Supporting Information is available free of charge at https://pubs.acs.org/doi/10.1021/acs.energyfuels.1c02031.

Tables S1 and S2 show the curve fitting of the spectra in Figure 5 (PDF)

\section{AUTHOR INFORMATION}

\section{Corresponding Author}

Teresa Mendiara - Department of Energy and Environment, Instituto de Carboquímica-ICB-CSIC, 50018 Zaragoza, Spain; (i) orcid.org/0000-0002-0042-4036;

Email: tmendiara@icb.csic.es

\section{Authors}

Arturo Cabello - Department of Energy and Environment, Instituto de Carboquímica-ICB-CSIC, 50018 Zaragoza, Spain

María Teresa Izquierdo - Department of Energy and Environment, Instituto de Carboquímica-ICB-CSIC, 50018 Zaragoza, Spain; (1) orcid.org/0000-0002-2408-2528

Alberto Abad - Department of Energy and Environment, Instituto de Carboquímica-ICB-CSIC, 50018 Zaragoza, Spain; 이이.org/0000-0002-4995-3473

Tobias Mattisson - Department of Space Earth \& Environment, Chalmers University of Technology, SE-412 96 Gothenburg, Sweden; (1) orcid.org/0000-0003-3942-7434

Juan Adánez - Department of Energy and Environment, Instituto de Carboquimica-ICB-CSIC, 50018 Zaragoza, Spain; 이이.orid.org/000-0002-6287-098X

Complete contact information is available at: https://pubs.acs.org/10.1021/acs.energyfuels.1c02031

\section{Funding}

We acknowledge the support of the European Regional Development Fund (ERDF) under the program "Programa Operativo FEDER Aragón 2014-2020 - Construyendo Europa desde Aragón: Proyecto BiosinCO2 (LMP180_18)”.

\section{Notes}

The authors declare no competing financial interest.

\section{ACKNOWLEDGMENTS}

T.M. acknowledges the "Ramón y Cajal" postdoctoral contract awarded by the Spanish Ministry of Economy and Competitiveness.

\section{REFERENCES}

(1) ONU United Nations Framework Convention for Climate Change. The Paris Agreement. http://unfccc.int/paris_agreement/ items/9485.php (accessed 2021-08-23).

(2) International Energy Agency (IEA). Outlook for Biomass and Biomethane. Prospects for Organic Growth (accessed 2021-08-23), 2020. www.iea.org.
(3) Rafiee, A.; Khalilpour, K. R.; Prest, J.; Skryabin, I. Biogas as an energy vector. Biomass Bioenergy 2021, 144, 105935.

(4) Petersson, A.; Wellinger, A. Biogas Upgrading TechnologiesDevelopments and Innovations. 2009. Www.iea-biogas.net (accessed 2021-08-23).

(5) Awe, O. W.; Zhao, Y. Q.; Nzihou, A.; Minh, D. P.; Lyczko, N. A Review of Biogas Utilisation, Purification and Upgrading Technologies. Waste Biomass Valorization 2017, 8 (2), 267-283.

(6) Rucker, C.; Kummerer, K. Environmental Chemistry of Organosiloxanes. Chem. Rev. 2015, 115 (1), 466-524.

(7) Dewil, R.; AppelS, L.; BaeyenS, J. Energy use of biogas hampered by the presence of siloxanes. Energy Convers. Manage. 2006, 47 (1314), $1711-1722$.

(8) Horii, Y.; Kannan, K. Survey of organosilicone compounds, including cyclic and linear siloxanes, in personal-care and household products. Arch. Environ. Contam. Toxicol. 2008, 55 (4), 701-710.

(9) Braganca, I.; Sanchez-Soberon, F.; Pantuzza, G. F.; Alves, A.; Ratola, N. Impurities in biogas: Analytical strategies, occurrence, effects and removal technologies. Biomass Bioenergy 2020, 143, 105878 .

(10) Tansel, B.; Surita, S. C. Oxidation of siloxanes during biogas combustion and nanotoxicity of Si-based particles released to the atmosphere. Environ. Toxicol. Pharmacol. 2014, 37 (1), 166-173.

(11) Wang, D. G.; Norwood, W.; Alaee, M.; Byer, J. D.; Brimble, S. Review of recent advances in research on the toxicity, detection, occurrence and fate of cyclic volatile methyl siloxanes in the environment. Chemosphere 2013, 93 (5), 711-725.

(12) Ryckebosch, E.; Drouillon, M.; Vervaeren, H. Techniques for transformation of biogas to biomethane. Biomass Bioenergy 2011, 35 (5), 1633-1645.

(13) Stern, S. A.; Krishnakumar, B.; Charati, S. G.; Amato, W. S.; Friedman, A. A.; Fuess, D. J. Performance of a bench-scale membrane pilot plant for the upgrading of biogas in a wastewater treatment plant. J. Membr. Sci. 1998, 151 (1), 63-74.

(14) Munoz, R.; Meier, L.; Diaz, I.; Jeison, D. A review on the stateof-the-art of physical/chemical and biological technologies for biogas upgrading. Rev. Environ. Sci. Bio/Technol. 2015, 14 (4), 727-759.

(15) Lee, W. Y.; Park, S. Y.; Lee, K. B.; Nam, S. C. Simultaneous Removal of $\mathrm{CO}_{2}$ and $\mathrm{H}_{2} \mathrm{~S}$ from Biogas by Blending Amine Absorbents: A Performance Comparison Study. Energy Fuels 2020, 34 (2), 1992-2000.

(16) Finocchio, E.; Montanari, T.; Garuti, G.; Pistarino, C.; Federici, F.; Cugino, M.; Busca, G. Purification of Biogases from Siloxanes by Adsorption: On the Regenerability of Activated Carbon Sorbents. Energy Fuels 2009, 23 (8), 4156-4159.

(17) Bak, C. U.; Lim, C. J.; Lee, J. G.; Kim, Y. D.; Kim, W. S. Removal of sulfur compounds and siloxanes by physical and chemical sorption. Sep. Purif. Technol. 2019, 209, 542-549.

(18) Lyngfelt, A.; Leckner, B.; Mattisson, T. A fluidized-bed combustion process with inherent $\mathrm{CO}_{2}$ separation; Application of chemical-looping combustion. Chem. Eng. Sci. 2001, 56 (10), 31013113.

(19) Mendiara, T.; García-Labiano, F.; Abad, A.; Gayán, P.; de Diego, L. F.; Izquierdo, M. T.; Adánez, J. Negative $\mathrm{CO}_{2}$ emissions through chemical looping technology. Appl. Energy 2018, 232, 657684.

(20) Lyngfelt, A. Chemical-Looping Combustion - Status and Development Challenges. Energy Fuels 2020, 34, 9077-9093.

(21) Abanades, J. C.; Arias, B.; Lyngfelt, A.; Mattisson, T.; Wiley, D. E.; Li, H.; Ho, M. T.; Mangano, E.; Brandani, S. Emerging $\mathrm{CO}_{2}$ capture systems. Int. J. Greenhouse Gas Control 2015, 40, 126-166.

(22) Adánez, J.; Abad, A. Chemical-looping combustion: Status and research needs. Proc. Combust. Inst. 2019, 37 (4), 4303-4317.

(23) Lyngfelt, A.; Leckner, B. A $1000 \mathrm{MW}_{\text {th }}$ boiler for chemicallooping combustion of solid fuels - Discussion of design and costs. Appl. Energy 2015, 157, 475-487.

(24) Gauthier, T.; Yazdanpanah, M.; Forret, A.; Amblard, B.; Lambert, A.; Bertholin, S. CLC, a promising concept with challenging development issues. Powder Technol. 2017, 316, 3-17. 
(25) Cabello, A.; Dueso, C.; García-Labiano, F.; Gayán, P.; Abad, A.; De Diego, L. F.; Adánez, J. Performance of a highly reactive impregnated $\mathrm{Fe}_{2} \mathrm{O}_{3} / \mathrm{Al}_{2} \mathrm{O}_{3}$ oxygen carrier with $\mathrm{CH}_{4}$ and $\mathrm{H}_{2} \mathrm{~S}$ in a 500 $\mathrm{W}_{\text {th }}$ CLC unit. Fuel 2014, 121, 117-125.

(26) Mendiara, T.; Izquierdo, M. T.; Abad, A.; de Diego, L. F.; García-Labiano, F.; Gayán, P.; Adánez, J. Release of pollutant components in CLC of lignite. Int. J. Greenhouse Gas Control 2014, $22,15-24$.

(27) Arnold, M.; Kajolinna, T. Development of on-line measurement techniques for siloxanes and other trace compounds in biogas. Waste Manage. 2010, 30 (6), 1011-1017.

(28) Schweigkofler, M.; Niessner, R. Determination of siloxanes and VOC in landfill gas and sewage gas by canister sampling and GC-MS/ AES analysis. Environ. Sci. Technol. 1999, 33 (20), 3680-3685.

(29) García-Labiano, F.; Gayán, P.; Adánez, J.; De Diego, L. F.; Forero, C. R. Solid waste management of a chemical-looping combustion plant using Cu-based oxygen carriers. Environ. Sci. Technol. 2007, 41 (16), 5882-5887.

(30) Zornoza, B.; Abad, A.; Mendiara, T.; Izquierdo, M. T. Ironbased Oxygen Carrier Particles Produced from Micronized Size Minerals or Industrial Wastes. Powder Technol. 2021, submitted.

(31) Mendiara, T.; Abad, A.; De Diego, L. F.; García-Labiano, F.; Gayán, P.; Adánez, J. Use of an Fe-based residue from alumina production as an oxygen carrier in chemical-looping combustion. Energy Fuels 2012, 26 (2), 1420-1431.

(32) Izquierdo, M. T.; García-Labiano, F.; Abad, A.; Cabello, A.; Gayán, P.; de Diego, L. F.; Adánez, J. On the optimization of physical and chemical stability of a $\mathrm{Cu} / \mathrm{Al}_{2} \mathrm{O}_{3}$ impregnated oxygen carrier for chemical looping combustion. Fuel Process. Technol. 2021, 215, 106740 .

(33) Abad, A.; García-Labiano, F.; de Diego, L. F.; Gayán, P.; Adánez, J. Reduction kinetics of $\mathrm{Cu}-, \mathrm{Ni}-$, and $\mathrm{Fe}$-based oxygen carriers using syngas $\left(\mathrm{CO}+\mathrm{H}_{2}\right)$ for chemical-looping combustion. Energy Fuels 2007, 21 (4), 1843-1853.

(34) CasaXPS Database. www.casaxps.com (accessed 2021-08-23).

(35) Adánez, J.; De Diego, L. F.; García-Labiano, F.; Gayán, P.; Abad, A.; Palacios, J. M. Selection of oxygen carriers for chemicallooping combustion. Energy Fuels 2004, 18 (2), 371-377.

(36) Bale, C. W.; Bélisle, E.; Chartrand, P.; Decterov, S. A.; Eriksson, G.; Gheribi, A. E.; Hack, K.; Jung, I. H.; Kang, Y. B.; Melançon, J.; Pelton, A. D.; Petersen, S.; Robelin, C.; Sangster, J.; Spencer, P.; Van Ende, M. A. FactSage thermochemical software and databases, 20102016. CALPHAD: Comput. Coupling Phase Diagrams Thermochem. 2016, 54, 35-53.

(37) Roine, A. HSC Chemistry; Metso Outotec Finland Oy: Tampere, Finland, 2018.

(38) Chubarov, V. A.; Masenkis, M. A.; Zherdev, Y. V.; Korolev, A. Y.; Avrasin, Y. D.; Andriano, K. Investigation of thermal-degradation of 3-dimensional polyorganosiloxanes. Vysokomolekulyarnye Soedineniya Seriya A 1973, 15 (12), 2627-2634.

(39) Baney, R. H. Some Organometallic Routes to Ceramics. In Ultrastructure Processing of Ceramics, Glasses and Composites, Ulrich, D. R., Hench, L. L., Eds.; John Wiley \& Sons, 1984.

(40) Belot, V.; Corriu, R. J. P.; Leclercq, D.; Mutin, P. H.; Vioux, A. Redistribution reactions in silsesquioxane gels. J. Mater. Sci. Lett. 1990, 9 (9), 1052-1054.

(41) Chagger, H. K.; Hainsworth, D.; Patterson, P. M.; Pourkashanian, M.; Williams, A. The formation of $\mathrm{SiO} 2$ from hexamethyldisiloxane combustion in counterflow methane-air flames. Symp. (Int.) Combust., [Proc.] 1996, 26, 1859-1865.

(42) Kuba, M.; Skoglund, N.; Ohman, M.; Hofbauer, H. A review on bed material particle layer formation and its positive influence on the performance of thermo-chemical biomass conversion in fluidized beds. Fuel 2021, 291, 120214.

(43) Gu, H.; Shen, L.; Zhong, Z.; Zhou, Y.; Liu, W.; Niu, X.; Ge, H.; Jiang, S.; Wang, L. Interaction between biomass ash and iron ore oxygen carrier during chemical looping combustion. Chem. Eng. J. 2015, 277, 70-78.
(44) Mei, D.; Mendiara, T.; Abad, A.; De Diego, L. F.; GarcíaLabiano, F.; Gayán, P.; Adánez, J.; Zhao, H. Manganese Minerals as Oxygen Carriers for Chemical Looping Combustion of Coal. Ind. Eng. Chem. Res. 2016, 55 (22), 6539-6546.

(45) de Diego, L. F.; García-Labiano, F.; Gayán, P.; Celaya, J.; Palacios, J. M.; Adánez, J. Operation of a $10 \mathrm{kWth}$ chemical-looping combustor during $200 \mathrm{~h}$ with a $\mathrm{CuO}-\mathrm{Al}_{2} \mathrm{O}_{3}$ oxygen carrier. Fuel 2007, 86 (7-8), 1036-1045.

(46) Abad, A.; Gayán, P.; García-Labiano, F.; de Diego, L. F.; Adánez, J. Relevance of plant design on CLC process performance using a Cu-based oxygen carrier. Fuel Process. Technol. 2018, 171, 7888. 